\title{
사회안전망 확충을 위한 개발원조 방향
}

조 정 현 $\mathrm{KOICA}$ 평가실 전문연구관

\section{목차}

I. 사회안전망 도입 배경과 개념

II. 사회안전망과 개발원조와의 관계

III. 국제사회의 흐름과 사회안전망 확충을 위한 노력

IV. 한국의 사회안전망 확충을 위한 개발원조 현황

$\mathrm{V}$. 향후 $\mathrm{KOICA}$ 개발원조 방향 및 함의

\section{I. 사회안전망 도입 배경과 개념}

97년 12월 불어닥친 경제위기는 한국 사회의 경제에 대한 인식을 바뀌놓았을 뿐만 아니라 사회 정책에 대한 담론들을 바꾸었다고해도 과언이 아니다(신광영,2002). 이 시기 이후의 사회정책이라 함은 경제개혁에 따른 대량의 실업으로 인해 빚어지는 빈곤과 불평등의 문제들을 완화하고 취약계 층이 사회적 위험(실업, 빈곤, 재해, 노령, 질병 등)에 노출되는 것을 방지하기 위한 완충 장치들의 성격을 띄었다. 이와 같은 사회 정책의 장치들은 소위 '사회적 안전망' 이라는 개념 하에 통용되었 는데, 한국에서의 사회안전망은 사회적 위기들로부터 보호하기 위한 사회보장제도의 일환인 '사회 보험과 공공부조' 등을 광의적 개념에서 시작된다.

국제사회에서 '사회안전망'의 개념은 세계은행, IMF 등이 개발도상국(이하 개도국)과 동구권국가 들에게 차관을 제공함과 동시에 구조조정을 요구하면서 발생하는 부작용 즉, 실업 및 생계곤란을 완 화시키기 위한 기제로부터 시작되었다. 1997년 아시아 경제위기를 통해, 우리나라는 물론 여타 개도 국들도 사회적 하부구조가 이러한 외부충격에 대한 대처능력이 없음을 여실히 드러냈다. (홍준표, 2006). 개도국은 외환 관리 문제 뿐 아니라 금융개혁, 재벌개혁, 공공부문 등이 총체적으로 문제를 안고 있었기 때문이다. 더구나 취약계층이 대다수인 개발도상국은 심화된 사회문제들을 깊이 경험하 
게 되었다. 그래서 긴박하고도 불가피하게 '시장소득에 의한 불평등 및 각종위험'에 대한 기본적 생 활권보장을 위해 포괄적인 성격의 장치인 '사회안전망 확충'에 대한 요구가 대내외적으로 커지게 되 었다(신광영, 2002).

실제로 많은 선진국 복지국가모형에서 따르면, 사회 안전망은 비대칭적인 경제구조를 완화하고, 불평등한 배분(allocation)에서 벗어나 사회의 양극화로 인한 문제를 해소하고 국가의 거버넌스1)를 강화하는데 도움을 준다는 것은 주목할 만하다. (김태성, 김진수, 2005; 신광영 2002).

주목할 점은, 거버넌스와 사회안전망 확충의 관계는 서로 한 싸이클(cycle)에 있다는 점이다. 바람직 한 거버넌스가 확립된 국가는 하부구조까지 잘 조직화된 형태를 기반으로 사회안전망 또한 보완적으로 확충하기 때문에 성공적으로 위기에 대응할 가능성이 높아진다(신광영, 2002 , 성경룡, 김태성).

그러나 앞에서도 언급했듯이, 경제적인 부흥을 꾀하고자하는 아시아 국가들 (소위, $\mathrm{APEC}$ 국가 들 -태국 등 )마저도 국가의 제도와 하부구조에 사회안전망을 이용하여 취약계층에 대한 보호를 제도화 하지 못하고 있으며 바람직한 거버넌스 확립 역시 자신할 수 없는 상황이다. 이렇게 외부위기의 충격 을 완화할 수 있는 준비가 되지 않은 상황가운데서, 충격완화층 역할을 해줄 '사회안전망 시행'은 기 대하기가 힘들어진다. 이는 개도국뿐만 아니라 빈민국으로 갈수록 위기에 더욱 취약하다는 것은 자 명한 일이다.

\section{II. 사회안전망과 개발원조관계}

사회안전망에서 중요한 이슈는 사회안전망을 구축 및 구현하고 촉진하는 '주체'가 누구이냐이다. 대 부분, 사회안전망은 정부관리 하에 공식적으로 법제화 되거나, 지역사회를 기반으로 비공식적으로 시 행되고 있는데, 단순히 국가의 거버넌스(governance)와 제도(system)의 수준과 역량 (질과 양)의 문 제뿐만 아니라 사회안전망을 법제화 시키고 시행할 만한 재원은 어떻게 충당할 것인가 또한 중요한 과 제이다2). 이 때문에 개도국에 경우, 거버넌스, 시스템(제도)의 부재 그리고 재원의 부족문제로 사회안 전망 구축을 주도적으로 하는 것이 쉽지 않다. 재원확보의 경우, 개도국은 안정적인 조세를 확보하기 어려워 외부로부터 원조받기도 한다(홍석표2006). 그러나 외부로부터 재원을 원조 받아 재원이 확보 된다 하더라도, 결국 거버넌스와 시스템의 제대로 구축되지 않는 이상 사회안전망의 구축 및 실현에

1) 거버넌스에 대한 정의와 범위는 다양하지만, 이글에서는 전통적인 집권적 관료구조에 바탕을 둔 행정을 대체하는 개념 (from Government to Governance)을 넘어서, 제도적, 법적, 행정적 안정과, 공공문제의 해결 등을 위해 협력하는 국 가, 시장, 시민사회를 연결하는 협력적 네트워크로서의 기능을 하는 (뉴)거버넌스의 개념을 축으로 논의하도록 하겠다.

2) 보통의 경우 재원은 정부가 직·간접적 이전을 통한 세수입으로 충당 
어려움이 있을 수 있다. 같은 맥락으로, 파리선언에서는 개발원조의 원조효과성(Paris Declaration on Aid Effectiveness)이 수원국의 거버넌스와 큰 연관성을 갖는다고 지적되어 왔다. 지난 개발원조 의 경험을 미루어 거버넌스가 확충되지 않으면 충분하게 원조의 질이 확보가 되기 어려우며 원조 피로 및 중첩 등을 해결할 수 없게 된다는 점을 발견했기 때문이다.

한편, 수원국이 능동적인 의지를 보이지 않는 상태에서 공여국은 적극적으로 수원국의 거버넌스에 개입하기 어렵기 때문에 수동적인 자세를 취하게 된다. 이와같은 이유로, 국제사회의 개도국에 대한 '사회안전망' 확충 혹은 거시적으로 '거버넌스 확립'을 위한 원조정책 혹은 지원 전략이 구체적으로 규명되어 제시되지 못하고 있다. 현실적으로, 개발도상국과의 협력 관계 안에서 공여국이 개발원조 의 일환으로 수원국의 Governance와 System(제도) 확립을 돕는다는 것이, 다소 정치적으로 민감한 부분으로 작용할 수 있고, 오히려 수원국의 원조의존적인 상황을 만들 수 있는 위험이 있기 때문이 다. 그렇다면, 위의 어려움과 한계점을 고려할 때, 국제사회의 대응 방안과 우리가 나아가야 할 방향 성 모색이 매우 절실하다. 이에 대한 논의는 다음 절의 국제사회와 한국(KOICA)의 흐름과 노력들의 사례 통하여 그 시사점과 해결방안을 제시해보고자 한다.

\section{III. 국제사회의 흐름과 사회안전망 확충을 위한 노력}

국제사회에서 초기의 "개발" 은 국가단위로의 경제적·양적 성장 중심의 발전관에 초점을 맞추어 왔 었다. 이와 같은 개발흐름 때문에 개발원조는 공여국이 수원국에 일방적으로 원조하는 개입주의적 국가주의 개발전략관계를 냉전체제 시대까지 유지해왔다. 그러나 원조효과성에 대한 의문과 함께 제 기된 개발 패러다임 자체의 전환을 요구하는 목소리들이 점차 커지기 시작하였다. 아마티아 센의 주 장과 같이 단순한 부의 증가가 아닌 “분배와 성장의 조화를 지향해야하며, 인간이 향유 가능한 진정 한 자유를 확대해 나가는 과정이 중요하다는 주장이 설득력을 얻기 시작했다(Sen, 1999). 이에따라 기존의 국가주도적이며 일방적인 공여국의 역할보다는 오히려, 조정자로서의 역할이 강조되는 국제 개발협력 체제로 변화되었다. 이러한 변화속에서, 빈곤감소전략 보고서(PRSP)를 보아도 알 수 있듯 이 세계은행들은 꾸준히 빈곤 감소 목표를 이루기 위한 수원국 정부의 자체적인 정책수립을 독려하 였고 공여국과 수원국 정부의 관계안에서도 개발정책에서 전략적 위치를 강화시키는 것의 중요성이 부각되었다(한국국제협력단, 2005).

그럼에도 불구하고, 전지구적으로 지속적인 빈곤심화를 경험하면서, 국제사회는 빈곤감소를 위한 새천년개발목표(Millenium Devleopment Goals)를 수립하였다. 이는 일방적인 개발원조방향성을 벗 어나, 다양한 글로벌 파트너십을 강화를 통해 빈곤감소를 위한 노력들이 일어나기 시작한 것을 의미 
했다. 특히, 바람직한 거버넌스 육성에 대한 중요성이 강조되기 시작하였는데, 이는 수원국 거버넌스 확충을 통해 사회안전망을 더욱 강화하여 사회적 위험으로부터 수원국 스스로 빈곤에 대응 할 수 있 는 능력을 기르고 취약계층의 보호할 수 있도록 하려는 노력들이었다. 이와 같은 내용은 2005 파리 선언(Paris Declaration on Effectivenss)에서도 그 중요성이 다시 재 강조된다. 파리선언에서 제시 한 원조효과성을 위한 5 가지 원조의 주요원칙 중 특히, 1) 수원국의 주인의식(Ownership), 2)수원국 개발전략에 공여국 원조의 일치(Alignment), 3) 공여국 간 원조조화(Harmonization), 5)공여국과 수원국 간 상호 책임성 강화(Mutual accountability) 등은 개발협력에서 중요한 수원국과의 관계와 수원국의 거버넌스, 역량강화를 위한 항목들로 볼 수 있겠다.

전지구적인 사회안전망 확충이라는 과제를 고려한다면, 파리선언에서 언급된 공여국간 원조조화는 개도국의 사회안전망을 확충하기 위해 선행되어야 하는 중요한 작업이다. 그 이유는 지원에 대한 불필 요한 중복과 관리상의 낭비를 피할 수 있기 때문이다. 실제로 지원의 중복은 개발원조의 효율성뿐 아니 라 책임성과 투명성마저 저하시키기 때문에 국가간의 원조 협력관계 속 사각지대를 찾아내는 작업이 중요하다. 이러한 빈곳을 찾기위해 국제사회안에서 사회적 위험요소 및 취약성평가, 사용가능한 재원, 급여의 부담, 제도효율성평가 등의 분류 방안등, 제도적인 합리화를 위한 담론형성이 진행 중이다.

이러한 담론과 국가 간의 합의가 성숙해진다면, 본격적으로 수원국의 거버넌스 확립을 통한 사회안 전망 확충으로 나아갈 수 있겠다. 파리선언에서 제시한 원조의 주요원칙을 바탕으로 보면 국제사회의 개발원조는 협력국 (Partner Country)이 주도적으로 거버넌스와 시스템(제도)을 강화하고 이를 통해 사회안전망을 이루어 나갈 수 있도록 공여국은 지지자 혹은 협력자로서의 파트너 역할을 지향한다는 것을 알 수 있다. 실제로, 개도국의 지원전략을 수립하는 과정에서 협력국의 정책 및 제도개선에 도움 을 줄 수 있도록 접근하려는 다양한 움직임들이 일어나고 있다. 특히, 국제사회는 개발도상국이 가지는 고유의 특성과 그들의 1)주인의식(Ownership)을 유지 강화하면서 5)공여국과 협력국 간 상호 책임성 강화할 수 있는 방안에 대해서 권고하고 있으며 이를 축으로 다음의 4 가지 주요관점을 제시하고 있다.

첫째로, 대부분의 개도국은 위기의 예측가능여부를 막론하고 긴박하게 발생할 수 있는 외부 위기 에 대응 할 수 있는 계획이 없을 가능성이 높다. 그러므로, 사회안전망은 기존의 제도를 유지하면서 구축되는 것이 효율성·효과성을 더욱 높일 수 있을 것이다. 신속하면서도 간단하게 기존의 수원국 제 도를 이용해 확충해 나가는 것이 제도를 보완하고, 실제 대상선정 방법을 이용해 위기 상황의 수요에 알맞게 신속히 확장될 수 있기 때문이다.

경제위기가 발생하자 위기 전 대응책을 충분히 계획하지 못했던 여러 아시아 국가들은 새로운 사 회안전망제도를 만들어 국민들을 지원해야만 했다. 이 때문에, 신속성과 대응성의 성격이 가장 중요 한 '사회안전망 제도'가 제 역할을 하는데 까지 시간이 지연되었으며 그 포괄성 역시 과도기적 성격 
을 띠어 효과성 및 효율성 부분에 문제점이 제기되었다. 그러나 이와는 달리, 라틴아메리카는 기존 의 탈빈곤제도들을 적극활용하여 사회안전망을 확충하였고, 인도네시아, 태국 등지에서는 공공근로 제도가 마련되어 실직자들의 소득을 지원한 바 있다.

둘째로, 수원국 중앙정부를 축으로 하부 부처간, 지방정부간 연계를 하는 것이 사회안전망 확충에 대한 정부 수뇌부와 그 하위구조에 영향력을 가진다고 권고한다. 또한 국가에서 모두 충당할 수 없는 재원을 충당하고 효율성을 제고하기 위해 공공민간분야간(PPP)의 파트너쉽 또한 강화되어야 함을 강조한다.

기본적으로 사회안전망은 사회적 위기에 놓인 취약계층이 민간제도나 가족 및 공동체단위의 대응 체계를 보완하는 성격을 가짐으로 사회안전망제도의 설계 및 시행책임을 중앙정부, 지방정부, 민간 단체 등에게 할당하는 형태로 가는 것이 제도관리의 효율성과 책임성을 위한 필요조건이 될 것이다. 예를 들어, 중앙 집권화되어 있는 아시아 국가들의 경우 경제위기 해소를 위해 지방차원에서 사회안 전망 제도를 시행하여 취약국민을 보호하는데는 한계가 있다. 실제 빈곤층 및 취약 대상계층에 대한 올바른 정보와 접근방법의 확보는 지방차원에서 가능하며, 빈곤층에 대한 제도시행에 있어서도 지방 정부가 더 높은 책임성을 보장할 수 있다는 점을 인식하면, 지방정부의 능력배양과, 각 부처간의 연 계가 필수적임을 알 수 있다.

그러므로 취약계층에 대한 보호기능을 약화시키지 않고 사회안전망제도를 탈집중화하려면 지방 정부의 능력이 필수적이며 그러한 능력을키우는 데는 상당한 시간이 걸리는 만큼 국제사회의 개발원 조의 방향성은 수원국의 '거버넌스 확립'의 기조 아래 국가의 수뇌부뿐만 아니라 지방정부역량강화와 연계하는 것이 중요한 과제가 아닐 수 없겠다.

같은 맥락에서, 셋째로 지역사회로부터의 접근(Community Level Approach)의 중요성을 다시 인 지해야하겠다. 지방정부의 역량을 개발하는 원래 취지는 직접적으로 취약계층과 더 밀접한 관계에 있다는 관점에서이다. 원래 전통적인 사회안전망의 주 대상은 기본 수급자의 범위가 '빈곤층'에만 국 한되었었다. 이를 고려했을 때, 개도국의 경우 인구의 $80 \%$ 이상이 빈곤층이므로 주 수혜 대상이 국가 전체가 되고 대상자 역시 모든 구성원, 계층, 연령, 성별을 포괄한다고 보아도 무방할 것이다. 그러 나 개발도상국일 수록 양극화가 심한 경향성 때문에 (신광영, 2002), 수원국의 빈곤구조를 면밀히 보 면 개도국역시 도시보다는 지방에 빈곤층의 대부분이 분포하고 있다는 점을 알 수 있다. 그러므로 지 방정부하의 지역단위, 하부구조를 구성하는 커뮤니티 단위의 사회의 결집을 살펴보면 빈부집단을 파 악하는데 더욱 용이하기 때문에 사회안전망제도의 구성과 대상을 명확히 할 수 있다는 것을 알 수 있 다(Raffer, Kunibert, 1999). 
즉, 사회안전망 확충을 위한 장기적인 접근으로 수원국 국가의 거버넌스 확립을 위한 노력이 이루어진 다면 중 - 단기적으로 커뮤니티를 축으로 하는 지역사회 개발을 위한 통합적인 접근이 필요하다. 대부분 의 사회안전망제도가 취약계층을 위해 사회보험과 같은 단기적인 성격을 띄는 지원 외에도 지역사회를 바탕으로 하는 인적자본개발, 고용기회제공, 생활환경 및 태도향상등을 지향하는 경향을 보이고 있는 것 또한 이를 뒷받침하는 것이라 볼 수 있겠다(홍석표, Erine Lightman, Peter Taylor- Gooby, 2006).

넷째로, 지역사회를 바탕으로 하는 커뮤니티 수준의 접근과 맞물려, 이를 더욱 구체화 시켜 줄 통 합적이고 다각적인개발원조 프로그램(Complexed or Package Programme)의 형성이 필요하다. 멕 시코의 경우 지역정부와 연합하여 빈곤경감 정책의 일환으로 조건부현금이전 프로그램(Conditional Cash Tranfer Programme; CCT) ${ }^{3)}$ 을 확대실시하고 있다. CCT는 지역사회를 기반으로 빈곤에 대한 다차원적인 관점으로 설계된 개발프로그램이라고 볼 수 있는데, 인적자본에 대한 투자를 위하여 영 양(Nutrition), 교육(Education), 보건(Health)분야를 통합적으로 접근하여 빈곤의 대물림을 막고 지 속적 경제적 개발 및 인적자원계발의 역할을 할 수 있는 사회안전망제도의 일환인 성공적인 프로그 램형 모델 평가 받고 있다( Rawlings and Rubio, 2004).

동 프로그램은 사회안전망 제도 프로그램의 일환으로서 그 효과성이 높다고 평가 되어 라틴아메리 카 전역으로 확대 실시되고 있는 실정이다. 현재 라틴아메리카를 넘어 인도, 인도네시아 등의 아시아 지역까지 시범적으로 시행되었다.

\section{IV. 사회안전망 확충을 위한 한국의 개발원조 현황}

공적개발원조(ODA) 자체가 경제적으로 글로벌 경제 및 자유시장에 낙오된 국가들(빈곤층)을 지원 하는 것이기 때문에, 2009 년 12 월 $\mathrm{OECD} / \mathrm{DAC}$ 가입한 한국은 국제사회 공여국의 일원으로서 국제사회 가 당면한 전지구적 '사회안전망 확충'이라는 과제와 이를 위해 요구되는 책임들을 간과할 수 없을 것 이다. 무상개발원조사업을 담당하고 있는 한국국제협력단(KOICA) 역시 앞에서 언급되었던 사회안전 망 확충을 위한 4 가지 주요 관점들을 바탕으로 개발원조의 방향성을 가지며 그 변화를 꾀하고 있다.

특히, 보건의료분야에 이러한 시도들이 활발히 진행되고 있는데, 가령, 네팔에 시행중인 '네팔의료 보험제도(2010 2012)가 이에 해당된다고 볼 수 있겠다. 동 사업은 네팔정부가 빈곤층과 소외층의

3) CCT를 단순현금이전(Cash Transfers; CT)과 비교하여 보면, CT는 경제적 충격을 비롯한 여러 가지 충격의 결과로 빚 어지는 문제점을 개개인이나 가구들이 더 잘 헤쳐나갈 수 있도록 돕는 사회부조의 도구이며 그리고 사회보호의 일환으 로써 사회보험 및 기타 사회부조, 현물이전 및 보조금과는 구별됨. CT는 주로 재분배 및 위험완화를 통한 빈곤경감 역 할을 한다고 평가 받으나 빈곤층의 제도의존을 불러 일으킨다는 비판을 받아왔음. 이와 같은 것을 해결하기 위하여, 조 건부(노동, 혹은 이행해야 하는 필수 사항, 여기서는 학교 출석, 클리닉 방문, 보건교육 참석 등) 이행사항들이 존재하 며, 이를 성실히 이행하였을 때 현금으로 돌려주는 형태를 취함. 
보건의료 서비스 접근성 향상을 위하여 빈곤층에 대한 필수 보건의료 서비스(ESSENTIAL HEALTH $\mathrm{CARE})^{4)}$ 를 무료화 하겠다는 계획을 바탕으로 이루어진 사업이다. 전반적으로 네팔정부의 무료 보건 의료 서비스 (Free Health Care)에 대한 정치적 - 사회적 의지는 아주 큼에도 불구하고 현실적으로 는, 구체적인 추진전략이 부재하고, 정부의 예산 및 관련인력 부족 등의 사유로 무료 보건의료 서비 스를 확대하는 데에는 어려움이 있는 상황이었다(2010, 한국국제협력단). 이에 네팔 정부는 예산문 제를해결하고 국민의 지속적인 건강증진을 도모하기 위한 수단으로 의료보험제도 도입을 할 수 있는 방안에 대해 고려하고 있었다. 과거 한국의 의료보험제도와 마찬가지로, 조합형태의 의료보험제도가 지금 현재 건강의료보험공단의 모태가 되었듯이, 현재의 네팔도 정부차원에서 추진하는 의료보험제 도는 없으나, 지역공동체간 또는 같은 직종간 실시하는 다양한 형태의 의료보험제도가 존재하는 것 으로 확인되었고 실제적으로 그중 일부는 성공적으로 시행되고 있었다.

이러한 점을 고려하여, $\mathrm{KOICA}$ 는 네팔의 사회 안전망확충을 위한 네가지 관점을 적극 도입하였다. 즉, 1) 기존의 제도를 적극 활용하는 방안으로 동 사업을 통해 기존에 존재하는 다양한 형태의 의료 보험제도를 최대한 존중하되, 2) 각부처, 지방정부, 민간단체를 적극 연계 활용하는 형태 보험 실행 주체를 다양화하여(지방정부, 병원, NGO, 지역공동체), 3) 지역사회 수준의 의료보험 모델을 수립하 였다. 이렇게 함으로써 중앙정부의 부담을 덜어줄뿐만 아니라 지방정부의 역량을 강화하고, 지역공 동체(Community)를 활성화하는 방안을 마련하는 계기가 되었다.

다른 예로, KOICA의 에티오피아의 '가족계획 및 모자보건 사업'(2009년 2011년)의 경우 보건의료 분야의 다각화된 패키지형(Package or Complexed Programme)프로그램의 시범적인 모델이라고 볼 수 있다. 동 사업은 에티오피아 중에서도 한 커뮤니티(헤토사 지역 가구)의 성격을 면밀히 분석하고 동 지역의 사회적 위험(높은 출산율 및 낮은 모자보건수준의 문제)을 파악하여 가족계획과 모자보건, 지역인력 강화 등의 사업을 통해 위험에 대응하고자 하였다. 이는 단순한 기존의 인프라 중심의 보건 분야 사업을 넘어서서 보건인력강화, 지역사회 의식개선(생활환경 개선 등을 위한 인식개선) 등을 통 한 지역사회의 역량강화를 위한 다각적인 접근이었다는 점에서 유의미하다고 볼 수 있다. 또한, 동사 업은 KOICA교육사업(가족계획 훈련센터 인근 KOICA 건립 중등학교, 주민교육센터 인근 KOICA 건 립초등학교) 및 지역개발사업과의 연계를 꾀하였고, 약 10 여개의 에티오피아 NGO와의 협력을 통해 기술자문, 가족계획 물자 및 정보공유 등을 가졌다. 이는 한정적인 재원과 부담이 될 수 있는 중앙집 권화를 완화하고 다양한 채널을 통해 사회안전망을 확충하고 시행하는 계기라고 할 수 있다.

또한, 지난 1993 년 이후 약 10 여년간 페루 모자보건 건강증진을 목적으로 한 보건분야 사업의 경 우, 빈민계층의 의료시설 접근도를 높이고, 협력국 내 최빈곤계층의 기초의료서비스 제공 및 질 높은

4) 네팔 정부는 필수 보건의료 서비스와 관련한 계획을 2006년 12월 15일 발표하고, 1 차 공공의료기관에서 빈곤층에 대한 무료 필수 보거의료 서비스를 시행하고 있음(네팔 의료보험제도 도입 타당성조사사업 사전결과보고서. 2010) 
의료서비스를 제공하기 위해 공중(모자)보건센터 건립사업을 하였다. 초기에는 단순 인프라 구축사 업으로 시작하였으나, 현재는 취약계층의 질병으로부터의 위험을 완화시키기 위한 페루 자체적인 모 자보건 교육 프로그램을 시행하는 센터 역할을 하고 있으며, 더 나아가 코이카 형 모자보건프로그램 혹은 질병관리프로그램 사업의 도입을 꾀하고 있는 등 다각적 접근의 프로그램형 사업형태로 진화하 는 가운데 있다. 특히, 페루 까야오(Callao)내에서도 '파차쿠텍'과 같이 빈민들이 모여 살던 지역인 도시 빈민촌에 병원을 건립함으로써 사회안전망 확충의 의미에 부합하다는 평가를 받고 있다. ${ }^{5)}$

\section{V. 향후 KOICA 개발원조 방향 및 함의}

이러한 노력에도 불구하고 아직도 한국 원조의 틀이 인프라 위주의 사업에 치중해 있다는 점을 부 인할 수 없을 것이다. 인프라에서 시작한 개발사업이 개도국의 하부구조(Bottom)의 필요를 충족하였 지만 제도, 정책 등과 같은 거버넌스를 통해 이룰 수 있는 더 큰 영향력을 기대하기에는 상위수준의 논의와 개발지원정책 및 국제협력전략(CPS)이 아직 부족한 상황이다. 또한, 협력국의 거버넌스 및 사회안전망 구축을 위해, 인프라 구축 사업 이후 지속가능한 개발을 돕는 내부 컨텐츠 및 프로그램이 부재하다. 여기서 간과하지 말아야 하는 것은, 한국은 협력국의 정부의 제도적 한계점 보완과 하부구 조의 지역사회의 지원을 병행적으로 이루어 나가야만 원조효과성의 파급효과를 증폭시킬수 있다는 점이다. 또한 전지구적 사회안전망의 구축을 위해서 한국은 한국 나름의 사회안전망 구축을 위한 방 향성을 가지고 있어야 한다. 국제사회의 흐름에서 보여진 4 가지 요건들이 물론 기본틀이 되겠지만, 가치지향적인 개발원조의 색, 곧 컨텐츠를 입혀 나가야 한다.

KOICA내에서의 협력국에 대한 온전한 정책적 이해가 요구되며, 그 구조에 대한 철저한 지식이 필 요하다 하겠다. 기존의 분야별 특성만이 강조된 단절적인 공여국의 원조 시스템에서 벗어나 분야 통 합적인 접근(Cross Sectional Approach)과 협력국가에 대한 개발정책전략(CPS)의 관계가 조화를 이 루어 나가야 하겠다(이와 같은 요구에 부응하기 위해 2011년 KOICA는 지역 부서로 조직을 재편, 협 력국에 맞는 원조사업의 틀을 다시 짜가고 있다는 것은 긍정적이라 할 수 있겠다).

원대한 목표(천년개발목표와 같은 거시적인 목표)가 물론 궁극적으로 중요하겠지만, 기본적으로 사회안전망이 취약계층의 성격(대상협력국의 대상자)을 고려하여 위험을 분산시킬 수 있다는 특징을 잊어서는 안 될 것이다. 더불어 사회안전망 확충을 위한 개발원조사업들이 제도적 차원에서의 포괄 적인 성격만을 가지는 것에서 그치는 게 아닌 지역사회수준에서의 촘촘한 그물망을 만들어가는 것을 놓치지 말아야 할 것이다.

5) 한국국제협력단, (2010), 페루6개 보건의료분야사업 사후종합평가 


\section{참고문헌}

\section{1. 국내문헌}

김태성, 김진수, 2005 , 사회보장론, 청목출판사

김태성, 성경륭, 2000 , 복지국가론, 나남출판사

신광영, 2002 , 한국의 경제위기와 복지개혁, 국가전략 제8권 1 호

이정우, 2005 , 성장과 분배, 그리고 사회보장, 보건복지포럼

정무성, 2006 , 양극화 문제 해소를 위한 사회 안전망 구축 방안, 사회과학논총, 제8집,

숭실대학교 사회과학연구원

홍석표, Lightman, Erine, Taylor-Gooby, Peter, 2006, APEC역내 사회안전망 강화의 논점과

국가별 사례연구보고서, 보건복지부 · 한국보건사회연구원

한국국제협력단, 2005 , 국제개발협력의 이해

, 2010, 네팔 의료보험제도 도입 타당성조사사업 사전조사 결과보고서

, 2010, 페루6개 보건의료사업 사후종합평가보고서

, 2010, 에티오피아 가족계획 및 모자보건사업 종료보고서

Raffer, Kunibert, 1999, ODA and Global Public Goods: A trend analysis of Paset and Present Spending Patterns, Office of development studies

Rawlings Laura B., Rubio, Gloria M., 2003, A new approach to social assistance : Latin America's experience with conditional cash transfer programs, Social Protection Discussion Papers 